\title{
Moving out the parental home and partnership formation as social determinants of low fertility
}

\author{
Albert Esteve $^{1, *}$, Diederik Boertien ${ }^{1}$, Ryohei Mogi ${ }^{1}$, and Mariona Lozano ${ }^{1}$
}

\section{The challenge}

The study of fertility across societies has been a core subject of demography, and is one of the main areas of theory development. As countries went from having fertility well above the replacement level to having fertility near the replacement level (2.1 children), one of the most widely accepted theoretical frameworks in demography emerged: the demographic transition. This transition was primarily driven by the social, health, and economic transformations associated with the general process of modernization (Notestein 1953; Lee 2003). But in many countries, fertility continued to decrease, falling to below the replacement level. The second demographic transition (SDT) was proposed to explain these changes (Van de Kaa 1987; Lesthaeghe 2014). The SDT placed more emphasis on ideational and cultural changes than on structural factors. Today, fertility below the replacement level is observed in virtually all high-income countries, and is spreading rapidly to other areas of the world. In 2017, 96 out of the 217 countries covered by the World Bank data reported total fertility rates of below 2.1 children per woman. Understanding the variations in fertility trends across these countries poses a new challenge for demography. To meet this challenge, we stress the need to identify and quantify the relative importance of the proximate social determinants of low fertility. We suggest that researchers investigating this issue pay particular attention to the effects of moving out of the parental home and partnership formation.

We argue that the broad social, cultural, and economic forces that were cited to explain the occurrence of the first and second demographic transitions do not necessarily suffice to explain the variations in fertility across countries and time after these transitions have taken place. Neither the idea that further development will eventually reverse the declining trend in fertility (Myrskylä et al. 2009), nor the abundance of micro-level studies on the many factors that are associated with childbearing (Balbo et al. 2013), have yielded convincing explanations for why

\footnotetext{
${ }^{1}$ Center for Demographic Studies, Barcelona, Spain

*Correspondence to: Albert Esteve, aesteve@ced.uab.es
} 
childbearing behaviour varies across low-fertility contexts. The idea that lowest-low fertility was just a stage in a process that would eventually lead to a recovery of fertility driven by advances in development or changes in gender relationships (Myrskylä et al. 2009; Goldscheider et al. 2015; Esping-Andersen and Billari 2015) has been challenged by recent declines in fertility in the alleged forerunner countries (e.g., Sweden and Norway). At the micro level of analysis, the growing availability of longitudinal data and the increasing sophistication of methods have resulted in an accumulation of findings documenting "causal" mechanisms affecting childbearing behaviour (Balbo et al. 2013). However, most of these findings have come from a selected group of countries (e.g., Germany, the United Kingdom, Nordic countries) for which data are available. Most importantly, it is not always clear how much these factors contribute to overall fertility levels at the macro level - and it is even less clear how much they contribute to cross-national differences in fertility rates.

To gain a better understanding of cross-national variations in low-fertility countries, we should aim to decompose cross-national variations in fertility rates based on a renewed set of proximate determinants of individual fertility decisions. Such an effort will require us to identify the proximate determinants of fertility at the individual level, and to quantify their contributions to the aggregate measures of fertility. We will also need to develop a broader understanding of how fertility decisions are constrained by desires and preferences for childbearing (and their importance relative to other life plans and projects), the biological limits to reproduction, and the resources and conditions required for achieving these goals. We argue that decomposition and standardization techniques can help us bridge the gap between the micro and macro levels of analysis when investigating how social institutions and national cultures penetrate the most personal aspects of peoples' lives. In the next section, we outline an analytical framework that may prove helpful in structuring this kind of analysis.

\section{A tentative framework}

We would like to suggest some basic elements and considerations that should be included in an analytical framework of below-replacement fertility in high-income countries. The framework proposed by Bongaarts is, of course, an inescapable point of reference for this effort (Bongaarts 1978). However, in the below-replacement era, several of the proximate determinants of fertility cited by Bongaarts have become less relevant (e.g., age at first intercourse, breastfeeding periods), while others remain just as important (e.g., fecundity and health). Here, we would like to start by emphasizing the following determinants.

First, fertility continues to be limited by fecundity. Assisted reproduction has extended the range of ages at which women can reproduce, but these extensions are more modest than the extensions of other social (e.g., expected age at first partnership or childbirth) and biological limits (e.g., life expectancy) that have taken place in recent decades. Thus, fertility decisions continue to be clearly constrained 
by age. Whereas age 50 is conventionally adopted as the end of a woman's reproductive years, problems with conception and the viability of pregnancies tend to emerge at much younger ages. The continued postponement of fertility decisions is in direct conflict with the ability to get pregnant after a certain age.

Second, the vast majority of children in low-fertility countries are wanted children. Women and men have control over their fertility decisions due to the widespread use of contraception and, in some countries, legal abortion. However, many women and men do not end up having all of the children they claim they would like to have. Three indicators summarize people's preferences regarding childbearing: ideal family size, ideal age at first birth, and voluntary childlessness. The data from low-fertility countries systematically show that the observed fertility level is below the ideal fertility level of around two children per woman, which has been constant over time and across Western countries (Sobotka and Beaujouan 2014). When available, the data on preferences regarding parenthood timing in low-fertility counties indicate that the normative age at first birth is rarely below 25 years (Testa 2007). Younger men and women may have plans to become parents in the future, but they do not necessarily intend to have children soon. Finally, it appears that less than $10 \%$ of women are voluntarily childless (Kreyenfeld and Konietzka 2017). These findings clearly indicate that the observed fertility trends are not in line with fertility preferences. Which determinants contribute to this gap between observed and desired fertility? How is this gap built over the life course, and how do differences in individual life courses accumulate to create cross-national differences?

To answer these questions, it is crucial that we identify the key period in people's lives in which cross-country differences in fertility can arise. This period is defined by two age limits: the normative age at first childbearing at the lower end (i.e., the point at which people are willing to start having children), and the biological limits of reproduction at the upper end (i.e., the point at which a woman is no longer fertile). The existing evidence from high-income countries with belowreplacement-level fertility indicates that cross-national differences arise between ages 25 and 40, and specifically among women in their thirties. Hence, assuming that science does not produce any major breakthroughs that extend the age limits of human reproduction, it appears that the window of time in the life course in which childbearing typically occurs is 10 to 15 years.

It is within this age range that we have to identify the additional proximate determinants of individual fertility, and quantify their contributions to macro-level rates of fertility. We argue that the two determinants that contribute the most to low fertility within this age range are leaving the parental home and partnership formation. Even today, the vast majority of births in high-income countries take place among co-residing couples, either married or cohabiting, who are economically independent and have their own housing. There are clear interactions between these two determinants. While a young person may leave the parental home and form a union at the same time, the likelihood that these two life transitions will coincide is declining (Buchmann and Kriesi 2011). There are also individuals who have a stable 
partner, but do not live with their partner (Levin 2004). We argue that partnership formation is the key element to focus on when studying determinants of fertility. While recent research has examined couple dynamics and gender relationships after union formation and their influence on fertility decisions, we hypothesize that the intensity and timing of partnership formation are the most important factors to consider when seeking to understand cross-national variations in fertility.

Both moving out of the parental home and forming a stable partnership have to be seen from a life course perspective, and are, therefore, age dependent. If people achieve certain conditions before or after they are in the range of ages for having children, as determined by normative and biological factors, it might have no influence on their fertility (Beaujouan et al. 2019). The literature on transitions to adulthood has documented extensively how these transitions affect fertility (e.g., Baizán et al. 2003), but it has not quantified how these transitions affect the crossnational differences in fertility rates we observe today. We hypothesize that the differences in fertility rates across low-fertility countries would be much smaller if all of the countries had similar rates of partnership formation and independent living between the ages of 25 and 40. A proper decomposition of fertility rates by the ages associated with and the duration of independent living arrangements and stable partnerships would be an important first step towards confirming our main hypothesis. It is through living independently and having a stable partnership that other social and economic changes affect fertility. For instance, cross-country differences in patterns of independent living and partnership formation might mirror cross-country differences in structural dynamics, such as labour market opportunities, access to childcare services, and housing. Societies might have different strategies for helping young people become economically independent and form stable partnerships, such as providing them with access to high-quality jobs and/or generous welfare state benefits. But it might be the case that once individuals in high-income countries have transitioned to living independently and have formed a partnership, the most important obstacles to childbearing they face have already disappeared.

\section{References}

Baizán, P., A. Aassve and F. C. Billari 2003. Cohabitation, marriage, and first birth: The interrelationship of family formation events in Spain. European Journal of Population/Revue européenne de Démographie 19(2): 147-169. https://doi.org/10.1023/A:1023343001627

Balbo, N., F. C. Billari and M. Mills 2013. Fertility in advanced societies: A review of research. European Journal of Population 29(1): 1-38. https://doi.org/10.1007/s10680012-9277-y

Beaujouan, É., A. Reimondos, E. Gray, A. Evans and T. Sobotka 2019. Declining realisation of reproductive intentions with age. Human Reproduction 34(10): 1906-1914. https: //doi.org/10.1093/humrep/dez150 
Bongaarts, J. 1978. A framework for analyzing the proximate determinants of fertility. Population and Development Review 4(1): 105-32. https://doi.org/10.2307/1972149

Buchmann, M. C. and I. Kriesi 2011. Transition to adulthood in Europe. Annual Review of Sociology 37: 481-503. https://doi.org/10.1146/annurev-soc-081309-150212

Esping-Andersen, G. and F. C. Billari 2015. Re-theorizing family demographics. Population and Development Review 41(1): 1-31. https://doi.org/10.1111/j.1728-4457.2015.00024.X

Goldscheider, F., E. Bernhardt and T. Lappegård 2015. The gender revolution: A framework for understanding changing family and demographic behavior. Population and Development Review 41(2): 207-239. https://doi.org/10.1111/j.1728-4457.2015.00045.x

Kreyenfeld, M. and D. Konietzka (eds) 2017. Childlessness in Europe: Contexts, causes, and consequences. Springer. https://doi.org/10.1007/978-3-319-44667-7

Lee, R. 2003. The demographic transition: three centuries of fundamental change. Journal of Economic Perspectives 17(4): 167-190. https://doi.org/10.1257/089533003772034943

Lesthaeghe, R. 2014. The second demographic transition: A concise overview of its development. Proceedings of the National Academy of Sciences 111(51): 18112-18115. https://doi.org/10.1073/pnas.1420441111

Levin, I. 2004. Living apart together: A new family form. Current Sociology 52(2): 223-240. https://doi.org/10.1177/0011392104041809

Myrskylä, M., H. P. Kohler and F. C. Billari 2009. Advances in development reverse fertility declines. Nature 460(7256): 741. https://doi.org/10.1038/nature08230

Notestein, F. W. 1953. Economic problems of population change. London: Oxford University Press.

Sobotka, T. and É. Beaujouan 2014. Two Is best? The persistence of a two-child family ideal in Europe. Population and Development Review 40(3): 391-419. https://doi.org/10.1111/j. 1728-4457.2014.00691.x

Testa, M. R. 2007. Childbearing preferences and family issues in Europe: Evidence from the Eurobarometer 2006 survey. Vienna Yearbook of Population Research 2007: 357-379. https://doi.org/10.1553/populationyearbook2007s357

Van de Kaa, D. J. 1987. Europe's second demographic transition. Population Bulletin 42(1): $1-59$.

Open Access This article is published under the terms of the Creative Commons Attribution 4.0 International License (https://creativecommons.org/licenses/by/4.0/) that allows the sharing, use and adaptation in any medium, provided that the user gives appropriate credit, provides a link to the license, and indicates if changes were made. 
